\title{
Bacosterol Glycoside, a New 13,14-Seco-steroid Glycoside from Bacopa monnieri $^{1)}$
}

\author{
Pamita Bhandari, Neeraj Kumar, Bikram Singh, and Vijay Kumar Kaul* \\ Natural Plant Products Division, Institute of Himalayan Bioresource Technology; Palampur, H.P. 176 061, India. \\ Received August 8, 2005; Accepted October 19, 2005
}

\begin{abstract}
A new sterol glycoside, bacosterol-3- $O$ - $\beta$-D-glucopyranoside along with bacopasaponin-C, bacopaside-I, bacopaside-II, bacosterol, bacosine and luteolin-7- $O$ - $\beta$-glucopyranoside have been isolated from Bacopa monnieri. Their structures were elucidated mainly on the basis of IR, 1D, 2D NMR (HMQC, HMBC, COSY), HR-ESI-QTOF-MS and EI mass spectral studies.
\end{abstract}

Key words Bacopa monnieri; Scrophulariaceae; bacosterol-3-O- $\beta$-D-glucopyranoside; bacopasaponin-C; bacopasides; bacosine

Bacopa monnieri (L) WeTTST. (Scrophulariaceae) is a reputed drug in Ayurveda for improvement of intelligence, memory and revitalization of sensory organs. ${ }^{2}$ Its alcoholic and hydroalcoholic extracts are reported to have nootropic activity, ${ }^{3-6)}$ due to the presence of two important dammarane type saponins namely bacoside-A and B. Other pharmacological activities like antioxidant, superoxide inhibition, analgesic and cognitive enhancing properties have also been reported. These activities have been attributed due to other type of dammarane saponins, which include bacosides $\mathrm{A}_{1}$ $\mathrm{A}_{3}$, bacopasaponins $\mathrm{A}-\mathrm{G}$ and bacopasides I-IV. In our attempt to isolate the marker compounds from $B$. monnieri, we have characterized a new sterol glycoside, bacosterol-3-O- $\beta$ D-glucopyranoside (1) together with known bacopasaponin-C (2), bacopaside-I (3), bacopaside-II (4), bacosterol (5), bacosine (6) and luteolin-7- $O-\beta$-D-glucopyranoside (7). Their structures were determined on the basis of spectroscopic methods $^{7-9)}$ and by comparison with authentic marker compounds.

\section{Results and Discussion}

Compound 1 appeared as a white amorphous powder. Its positive HR-ESI-QTOF-MS showed a peak at $\mathrm{m} / \mathrm{z}$ (599.8395) $[\mathrm{M}+\mathrm{Na}]^{+}$, (Calcd for $\mathrm{C}_{35} \mathrm{H}_{60} \mathrm{O}_{6} \mathrm{Na}$ 599.8247) consistent with a molecular formula $\mathrm{C}_{35} \mathrm{H}_{60} \mathrm{O}_{6} \mathrm{Na}$. The IR spectrum showed absorption bands for a double bond $\left(1640 \mathrm{~cm}^{-1}\right)$ and for hydroxyl groups $\left(3450 \mathrm{~cm}^{-1}\right)$. Its ${ }^{1} \mathrm{H}-$ NMR spectrum (Table 1) exhibited three signals for olefinic protons at $\delta_{\mathrm{H}} 5.31(1 \mathrm{H}, \mathrm{m}, \mathrm{H}-11), 5.16(1 \mathrm{H}, \mathrm{m}, \mathrm{H}-15)$ and $5.13(1 \mathrm{H}, \mathrm{d}, \mathrm{H}-14, J=6.6 \mathrm{~Hz})$ indicating the presence of two double bonds. The characteristic signal for anomeric proton was observed at $\delta 5.05(\mathrm{~d}, J=7.8 \mathrm{~Hz})$, the $J$ value suggested the $\beta$-configuration of the glucose unit. ${ }^{1} \mathrm{H}-{ }^{1} \mathrm{H}$ COSY experiment exhibited correlation between $\mathrm{H}-11\left(\delta_{\mathrm{H}} 5.31\right)$ and $\mathrm{H}-12$ $\left(\delta_{\mathrm{H}} 1.05 \alpha, 1.85 \beta\right), \mathrm{H}-13\left(\delta_{\mathrm{H}} 1.51\right)$ and $\mathrm{H}-17\left(\delta_{\mathrm{H}} 1.45\right), \mathrm{H}-14$ $\left(\delta_{\mathrm{H}} 5.13\right)$ and $\mathrm{H}-15\left(\delta_{\mathrm{H}} 5.16\right), \mathrm{H}-8\left(\delta_{\mathrm{H}} 1.35\right)$ and $\mathrm{H}-14\left(\delta_{\mathrm{H}}\right.$ $5.13), \mathrm{H}-15\left(\delta_{\mathrm{H}} 5.16\right)$ and $\mathrm{H}-16\left(\delta_{\mathrm{H}} 1.61 \alpha, 1.12 \beta\right)$ indicating the absence of bond between $\mathrm{C}-13$ and $\left.\mathrm{C}-14 .{ }^{9}\right)$ In decoupled ${ }^{13} \mathrm{C}$-NMR spectrum of compound $\mathbf{1}$ (Table 1), the spectrum displayed signals for 35 carbons; of which 29 were assigned to the aglycone moiety and remaining 6 were assigned to the glucose moiety which included one anomeric carbon signal at $\delta_{\mathrm{C}} 103.8$ and olefinic carbons at $\delta_{\mathrm{C}} 142.0,123.0,131.0$, and 140.0. The presence of 6 methyl, eleven methylene, 11 methine and two quaternary carbon atoms were confirmed by
DEPT experiments. The ${ }^{1} \mathrm{H}$ - and ${ }^{13} \mathrm{C}-\mathrm{NMR}$ data of aglycone moiety of $\mathbf{1}$ was found to be similar to that of bacosterol. The attachment of glucose unit at C-3 was confirmed by its downfield shift $\left.{ }^{10,11}\right)$ in ${ }^{13} \mathrm{C}-\mathrm{NMR}$ value $\left(\delta_{\mathrm{C}} 79.9\right)$. The HMBC correlation of anomeric proton further confirmed that the glu-

Table 1. ${ }^{1} \mathrm{H}$ - and ${ }^{13} \mathrm{C}-\mathrm{NMR}$ Spectral Data of Compound $\mathbf{1}(300,75 \mathrm{MHz}$ in Py- $d_{5}$ ) and Bacosterol ${ }^{9)}$

\begin{tabular}{|c|c|c|c|c|}
\hline \multirow{2}{*}{ Position } & \multirow{2}{*}{$\delta_{\mathrm{C}}$} & \multicolumn{2}{|c|}{$\delta_{\mathrm{H}} \mathrm{m}(J \mathrm{~Hz})$} & \multirow{2}{*}{$\begin{array}{c}\delta_{\mathrm{C}} \\
\text { Bacosterol }^{9)}\end{array}$} \\
\hline & & $\alpha$ & $\beta$ & \\
\hline 1 & 38.7 & $\begin{array}{l}1.34 \mathrm{ddd}(16.11, \\
9.5,5.3)\end{array}$ & $\begin{array}{l}2.28 \text { ddd }(12.5, \\
5.9,3.41)\end{array}$ & 37.2 \\
\hline 2 & 33.4 & $1.86 \mathrm{~m}$ & $1.83 \mathrm{~m}$ & 31.6 \\
\hline 3 & 79.9 & $4.29 \mathrm{~m}$ & - & 71.7 \\
\hline 4 & 42.0 & $2.41 \mathrm{~m}$ & $1.95 \mathrm{~m}$ & 42.2 \\
\hline 5 & 52.0 & $1.61 \mathrm{~m}$ & - & 50.1 \\
\hline 6 & 24.5 & $1.46 \mathrm{~m}$ & $1.43 \mathrm{~m}$ & 24.3 \\
\hline 7 & 25.7 & $1.55 \mathrm{~m}$ & $1.25 \mathrm{~m}$ & 23.0 \\
\hline 8 & 51.0 & $1.35 \mathrm{~m}$ & - & 51.2 \\
\hline 9 & 142.0 & - & - & 140.7 \\
\hline 10 & 36.0 & - & - & 36.4 \\
\hline 11 & 123.0 & $5.31 \mathrm{~m}$ & - & 121.7 \\
\hline 12 & 35.4 & $1.05 \mathrm{~m}$ & 1.85 & 33.9 \\
\hline 13 & 40.4 & $1.51 \mathrm{~m}$ & - & 40.4 \\
\hline 14 & 131.0 & $5.13 \mathrm{~d}(6.6)$ & - & 129.2 \\
\hline 15 & 140.0 & $5.16 \mathrm{~m}$ & - & 138.3 \\
\hline 16 & 28.2 & $1.61 \mathrm{~m}$ & $1.12 \mathrm{~m}$ & 28.2 \\
\hline 17 & 58.0 & $1.45 \mathrm{~m}$ & - & 56.0 \\
\hline 18 & 13.6 & $0.63 \mathrm{~d}(6.6)$ & - & 11.9 \\
\hline 19 & 22.7 & $1.00 \mathrm{~s}$ & - & 19.3 \\
\hline 20 & 37.5 & - & $2.01 \mathrm{~m}$ & 36.1 \\
\hline 21 & 20.6 & $0.89 \mathrm{~d}(7.2)$ & - & 18.7 \\
\hline 22 & 38.7 & $1.53 \mathrm{~m}$ & $1.05 \mathrm{~m}$ & 39.7 \\
\hline 23 & 26.5 & $1.26 \mathrm{~m}$ & $1.79 \mathrm{~m}$ & 26.0 \\
\hline 24 & 47.7 & $4.18 \mathrm{~m}$ & - & 45.8 \\
\hline 25 & 30.5 & $1.45 \mathrm{~m}$ & - & 29.1 \\
\hline 26 & 20.4 & $0.89 \mathrm{~d}(6.6)$ & - & 19.8 \\
\hline 27 & 20.2 & $0.86 \mathrm{~d}(6.3)$ & - & 19.0 \\
\hline 28 & 31.5 & $1.14 \mathrm{~m}$ & $1.51 \mathrm{~m}$ & 31.8 \\
\hline 29 & 13.6 & $0.89 \mathrm{~d}(5.8)$ & - & 11.8 \\
\hline $1^{\prime}$ & 103.8 & $5.05 \mathrm{~d}(7.8)$ & & \\
\hline $2^{\prime}$ & 76.6 & $3.99 \mathrm{dd}(7.8,8.4)$ & & \\
\hline $3^{\prime}$ & 79.8 & $4.18^{a)}$ & & \\
\hline $4^{\prime}$ & 72.6 & $4.19^{a)}$ & & \\
\hline $5^{\prime}$ & 79.3 & $3.89 \mathrm{~m}$ & & \\
\hline $6^{\prime}$ & 64.2 & $\begin{array}{l}4.30 \mathrm{dd}(11.7,4.8) \\
4.45 \mathrm{~d}(11.7)\end{array}$ & & \\
\hline
\end{tabular}

a) Signals are overlapped by other signals and therefore their multiplication could not be determined. 


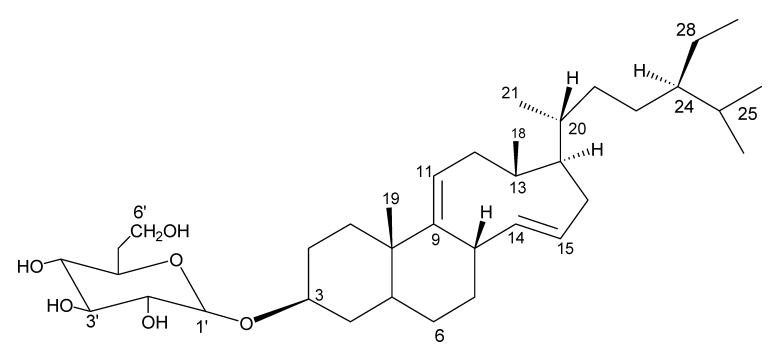

Fig. 1. Structure of Compound 1

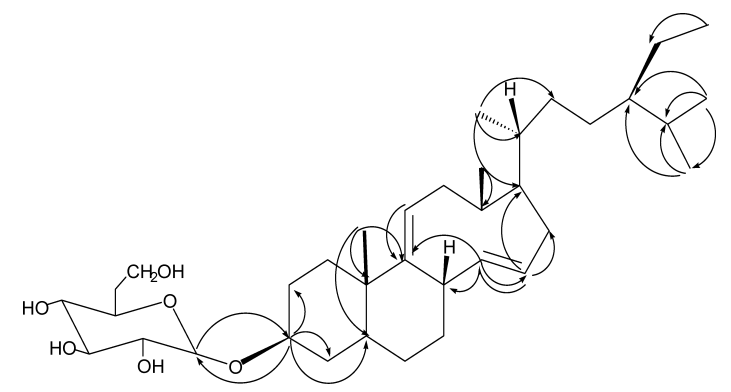

Fig. 2. Key $\operatorname{HMBC}(\rightarrow)$ of Compound 1

cose unit was attached at $\mathrm{C}-3$ of the aglycone moiety. The $2 \mathrm{D}$ NMR spectral techniques (COSY, HMQC, HMBC) permitted assignments for all ${ }^{1} \mathrm{H}$ and ${ }^{13} \mathrm{C}$ signals of $\mathbf{1}$. Acid hydrolysis of $\mathbf{1}$ yielded a sugar unit and an aglycone. Sugar unit was characterized as glucose by its TLC with an authentic sample of glucose. Aglycone moiety was identified as bacosterol by comparison of its ${ }^{1} \mathrm{H}$ - and ${ }^{13} \mathrm{C}$-NMR spectral data with reported values. ${ }^{9)}$

The MS/MS spectra of 599 in positive ESI-QTOF-MS/MS produced fragment ions at $\mathrm{m} / \mathrm{z} 414$ and 444 representing glycosidic cleavage $[\mathrm{M}+\mathrm{Na}-\text { glucose }-\mathrm{Na}]^{+}$and side chain $\left[\mathrm{M}+\mathrm{Na}-\mathrm{C}_{11} \mathrm{H}_{23}\right]^{+}$, respectively. The EI-MS of $\mathbf{1}$ showed molecular ion peak at $m / z 576$ and the presence of a fragment at $m / z 414$ suggested loss of one glucose unit [M-glucose $]^{+}$. Other mass fragments were found to be similar as reported earlier for bacosterol. ${ }^{9}{ }^{9}$ Thus, on the basis of above evidences compound $\mathbf{1}$ was unambiguously characterized as bacosterol3-O- $\beta$-D-glucopyranoside.

Other isolated compounds, $2,3,4,5,6$ and 7 were characterized by comparison of their ${ }^{1} \mathrm{H}-$ and ${ }^{13} \mathrm{C}-\mathrm{NMR}$ spectra with reported values. ${ }^{7-9)}$

\section{Experimental}

General Melting points were determined on a Mettler FP800 (Central Processor) and are uncorrected. Optical rotation was determined on Polarimeter of Advance Research Instrument Co. India (PA-IR). IR spectrum was recorded in $\mathrm{KBr}$ disk on a Jasco FT-IR-5300. ESI and EI mass spectra were recorded on Waters QTOF- micro mass and on Shimadzu GCMSQP2010 respectively. ${ }^{1} \mathrm{H}$ - and ${ }^{13} \mathrm{C}-\mathrm{NMR}$ spectra were recorded in Bruker Avance-300. Column chromatography was carried out with Merck silica gel 60-120 mesh. TLC was run on Merck aluminium pre-coated silica gel 60 $\mathrm{F}_{254}$ plates. Spots were visualized by vanillin-sulphuric acid spray reagent. All the chemicals used were purchased from Merck India Ltd.

Plant Material The plant material was collected in May 2004 from Medicinal Plants Research Institute in ISM, Joginder Nagar, Himachal Pradesh, India.
Extraction and Isolation The air-dried and powdered aerial parts of Bacopa monnieri $\left(2.2 \mathrm{~kg}\right.$ ) were defatted with petroleum ether (bp $60^{\circ}$ $80^{\circ} \mathrm{C}$ ) in a soxhlet apparatus. The defatted material was then extracted three times with $\mathrm{MeOH}$ in a percolator at room temperature. The combined $\mathrm{MeOH}$ extract was concentrated and kept overnight at room temperature and filtered. The separated deep green residue-A (18g) was washed with methanol three times. The filtrate was diluted with water and partitioned successively with EtOAc and $n-\mathrm{BuOH}$. The EtOAc and $n$-BuOH fractions on removal of solvent yielded $43.3 \mathrm{~g}$ and $57.9 \mathrm{~g}$ residue respectively. EtOAc fraction $(43.3 \mathrm{~g})$ was subjected to column chromatography on silica gel $(60-120 \mathrm{mesh})$ using a gradient elution of $\mathrm{CHCl}_{3}: \mathrm{MeOH}$ with increasing proportion of $\mathrm{MeOH}$. Fractions eluted with $\mathrm{CHCl}_{3}: \mathrm{MeOH}(95: 5)$ furnished compound 1 (31 mg) as white powder after crystallization in methanol. Fractions eluted with $\mathrm{CHCl}_{3}: \mathrm{MeOH}(90: 10)$ yielded bacosterol $(300 \mathrm{mg})$. Fractions eluted with $\mathrm{CHCl}_{3}: \mathrm{MeOH}(98: 2)$ afforded bacosine $(200 \mathrm{mg})$ and luteolin-7-O- $\beta$-glucopyranoside ( $25 \mathrm{mg}$ ).

Similarly, $n$-BuOH fraction (57.9 g) was subjected to column chromatography over silica gel $(60-120$ mesh $)$ using gradient elution of $\mathrm{CHCl}_{3}: \mathrm{MeOH}$ with increasing proportion of $\mathrm{MeOH}$. Fractions eluted with $\mathrm{CHCl}_{3}: \mathrm{MeOH}(85: 15)$ were further purified by repeated column chromatography on silica gel and afforded bacopasaponin-C $(27 \mathrm{mg})$ in $\mathrm{CHCl}_{3}: \mathrm{MeOH}(80: 20)$.

The deep green residue-A (18g) was subjected to column chromatographic separation on silica gel (60-120 mesh) using a gradient elution of $\mathrm{CHCl}_{3}: \mathrm{MeOH}$ with increasing proportion of $\mathrm{MeOH}$. Fractions eluted with $\mathrm{CHCl}_{3}: \mathrm{MeOH}(90: 10)$ afforded bacopaside-I $(27 \mathrm{mg})$ on crystallization with $\mathrm{MeOH}$. Fractions eluted with $\mathrm{CHCl}_{3}: \mathrm{MeOH}(70: 30)$ were further purified by column chromatography on silica gel yielded bacopaside-II (32 mg).

Bacosterol-3- $O$ - $\beta$-D-glucopyranoside (1): White amorphous powder. $[\alpha]_{\mathrm{D}}^{25}$ $-30.2^{\circ}\left(c=6.6 \times 10^{-4}, \mathrm{MeOH}\right) . \mathrm{mp}$ uncorrected. IR $(\mathrm{KBr}) \mathrm{cm}^{-1}: 3450$, 2940, 2860, 1640, 1465, 1380, 1050, 960, 950, 845, 805. ${ }^{1} \mathrm{H}-$ and ${ }^{13} \mathrm{C}-\mathrm{NMR}$ (300, $75 \mathrm{MHz}$ ) spectral data: see Table 1. HR-ESI-QTOF-MS $m / z: 599.8395$ $[\mathrm{M}+\mathrm{Na}]^{+},\left(\right.$Calcd for $\left.\mathrm{C}_{35} \mathrm{H}_{60} \mathrm{O}_{6} \mathrm{Na} 599.8247\right)$. EI-MS $m / z: 576\left[\mathrm{C}_{35} \mathrm{H}_{60} \mathrm{O}_{6}\right]^{+}$, $414,396,351,273,255,186,160,175,240,231,213,201,199,159,145$, $133,119,107,95,85,71,57,43$.

Acid Hydrolysis of 1 Compound $1(15 \mathrm{mg})$ was refluxed with $2 \mathrm{~N} \mathrm{HCl}$ in aqueous $\mathrm{MeOH}(10 \mathrm{ml})$ for $6 \mathrm{~h}$. The reaction mixture was cooled, diluted with water $(10 \mathrm{ml})$ and extracted with EtOAc. The aqueous part was neutralized with saturated solution of $\mathrm{Na}_{2} \mathrm{CO}_{3}$ and filtered. The filtrate was concentrated under reduced pressure and examined for sugar identification on TLC with authentic sample of glucose. EtOAc residue was purified to yield aglycone and its structure was elucidated by ${ }^{1} \mathrm{H}$ - and ${ }^{13} \mathrm{C}-\mathrm{NMR}$.

Acknowledgements Authors are thankful to Dr. P. S. Ahuja (Director, IHBT, Palampur) for providing necessary facilities during the course of this work.

\section{References and Notes}

1) IHBT communication No. 0538.

2) Garai S., Mahato S. B., Ohtani K., Yamasaki K., Phytochemistry, 43, 447-449 (1996)

3) Sivranjan V. V., Balachandran I., "Ayurvedic Drugs and Their Plant Sources," Oxford and IBH publishing CO., New Delhi, 1994.

4) Deepak M., Amit A., Phytomedicine, 11, 264-268 (2004).

5) Singh H. K., Dhawan B. N., J. Ethnopharm., 5, 305-314 (1982).

6) Prakash J. C., Sirsi M., J. Sci. Ind. Res., 21, 93-96 (1962).

7) Garai S., Mahato S. B., Ohtani K., Yamasaki K., Phytochemistry, 42, 815-820 (1996).

8) Chakaravarty A. K., Sarkar T., Masuda K., Shiojima K., Nakane T., Kawahara N., Phytochemistry, 58, 553-556 (2001).

9) Ahmed B., Rahman A., Ind. J. Chem., 39B, 620-625 (2000).

10) Joshi B. S., Moore K. M., Pelletier S. W., J. Nat. Prod., 55, 1468 1476 (1992).

11) Nie R. L., Tanka T., Miyakoshi M., Kasai R., Morita T. B., Zhou J., Tanaka O., Phytochemistry, 28, 1711-1715 (1989). 